\title{
Properties of Nb-doped ZnO transparent conductive thin films deposited by rf magnetron sputtering using a high quality ceramic target
}

\author{
J W XU, H WANG, M H JIANG* and X Y LIU \\ Guangxi Key Laboratory of Information Materials, Guilin University of Electronic Technology, \\ Guilin 541004, China
}

MS received 2 January 2009; revised 25 March 2009

\begin{abstract}
Nb-doped $\mathrm{ZnO}$ films with (002) orientation have been grown on glass substrates by rf magnetron sputtering followed by vacuum annealing at $400^{\circ} \mathrm{C}$ for $3 \mathrm{~h}$. The microstructures and surface figures of the $\mathrm{Nb}-$ doped ZnO films were investigated with X-ray diffraction (XRD) and scanning electron microscopy (SEM), respectively. And its optical and electrical properties were measured at room temperature using a four-point probe technique and 756-type spectrophotometer, respectively. X-ray diffraction (XRD) revealed that the films are highly textured along the $c$ axis and perpendicular to the surface of the substrate. After annealing at $400^{\circ} \mathrm{C}$ for $180 \mathrm{~min}$ under vacuum, transmittance of about $90 \%$ in visible region for $\mathrm{Nb}$ doped $\mathrm{ZnO}$ films was confirmed by the optical transmission spectra, and the low resistivity of $5 \cdot 47 \times 10^{-3} \Omega \cdot \mathrm{cm}$ was obtained.
\end{abstract}

Keywords. ZnO films; Nb-doped; magnetron sputtering; optical and electrical properties.

\section{Introduction}

Transparent conducting oxides (TCOs) have found applications in several optoelectronic devices such as light emitting diodes (LEDs), solar cells, and flat panels as well as flexible displays (Srikant and Clarke 1998; Cui et al 2005; Hsieh et al 2007). Indium tin oxide (ITO) is the most commonly used TCO for these applications because of its high transmittance in the visible region and a resistivity close to $1.0 \times 10^{-4} \Omega \cdot \mathrm{cm}$ (Paraguay et al 1999). However, high cost and scarce resources of In limit its usage in these devices. This has led researchers to explore alternative materials for the TCO applications. Some of the TCOs which have shown transmittance and resistivity values close to those of ITO are $\mathrm{ZnO}: \mathrm{Al}$, $\mathrm{ZnO}: \mathrm{Ga}, \mathrm{F}: \mathrm{SnO}_{2}, \mathrm{Nb}: \mathrm{TiO}_{2}$ and so on. Among these, $\mathrm{ZnO}$ is the most favourable material because of its benign nature, relatively low cost, good stability in hydrogen plasma process, and non-toxicity (Paraguay et al 1999; Joseph et al 2001). After doping, $\mathrm{ZnO}$ as a semiconductor will become conductive. Therefore, there is a considerable interest in understanding the electrical and transport properties of doped $\mathrm{ZnO}$ films, which is critical for further improvement of TCOs characteristics.

Most of the careful doping studies have been performed by the kinds of techniques in order to improve the performance of $\mathrm{ZnO}$ films (Srikant et al 1995; Tang et al 1998; Paraguay et al 1999; Minami et al 2001; Dang et al 2007; Saito et al 2007). Doping with Al, Ga, In and so

*Author for correspondence (jmhsir@tom.com) on, has been attempted by many groups, resulting in high-quality, highly conductive $n$-type $\mathrm{ZnO}$ films (Cao et al 2004; Özgü et al 2005). Recently, $n$-type $\mathrm{ZnO}$ films doped with other elements such as rare earth, W, Zr and so on has been prepared by different methods (Swanepoel 1983; Sarkar et al 1991; Fujimura et al 1993). To our knowledge, there is no report for single $\mathrm{Nb}$ doped $\mathrm{ZnO}$ films. In this paper, we report $\mathrm{Nb}$-doped $\mathrm{ZnO}$ films grown on glass substrates at room temperature by $\mathrm{rf}$ magnetron sputtering and post vacuum annealing process.

\section{Experimental}

\subsection{Preparation of ceramic targets}

The raw materials were the commercially available $\mathrm{ZnO}$ and $\mathrm{Nb}_{2} \mathrm{O}_{5}$ (99.95\% in purity). Mechanical mixed powders, as the raw materials, were treated by die pressing and normal pressing, and then sintered at $1300^{\circ} \mathrm{C}$ for $4 \mathrm{~h}$ in air. The following compositions were chosen: $98 \%$ $\mathrm{ZnO}+2 \% \mathrm{Nb}_{2} \mathrm{O}_{5}$ (wt \%). The linear shrinkage ratios of the sintered targets reached about $22 \%$ and the relative density was about $95 \%$.

\subsection{Preparation of thin films}

Room temperature deposition of high quality transparent conductive thin films is an advantage to industrial production. $\mathrm{Nb}$-doped $\mathrm{ZnO}$ thin films were deposited on glass substrates using the ratio frequency (rf) magnetron 
sputtering technique. The glass substrates were thoroughly cleaned ultrasonically using ethanol absolute, acetone and distilled water as solvents and then dried prior to be loaded into deposition chamber. Sputtering was carried out at room temperature with a targetsubstrate distance of $67 \mathrm{~mm}$ and a sputtering gas pressure of $1.6 \mathrm{~Pa}$. The chamber was evacuated to a base pressure of $8 \times 10^{-5} \mathrm{~Pa}$. A sputter-etch of $15 \mathrm{~min}$ was used to remove the target surface contamination. Finally, argon gas was introduced, and the gas pressure was adjusted. The substrate temperature was at room temperature. The sputtering power was $110 \mathrm{~W}$. In order to produce more oxygen vacancies, oxygen was not used during the deposition. The samples were annealed at $400^{\circ} \mathrm{C}$ for $3 \mathrm{~h}$ under vacuum $\left(\sim 10^{-1} \mathrm{~Pa}\right)$. The thickness of the films was about $500 \mathrm{~nm}$.

Crystallographic and phase structures of the as-grown $\mathrm{Nb}$-doped $\mathrm{ZnO}$ films were determined by X-ray diffraction (XRD) (D8-Advance) with $\mathrm{CuK} \alpha$ radiation. The scanning electron microscope (SEM) (JSM-5610LV) was used to investigate the surface morphology and measure the thickness of the films. Optical measurements (absorption and transmission) were made for photon wavelengths ranging from 300-900 nm, using a spectrophotometer (UV-756). During the spectrum testing, as a contrast the absorption spectrum of the bare substrate was already eliminated. The electrical resistivity was measured using a four-point probe technique (RTS-8) at room temperature.

\section{Results and discussion}

\subsection{Structural studies}

Figure 1 shows the X-ray diffraction (XRD) patterns of the $\mathrm{Nb}$-doped $\mathrm{ZnO}$ films prepared at room temperature.

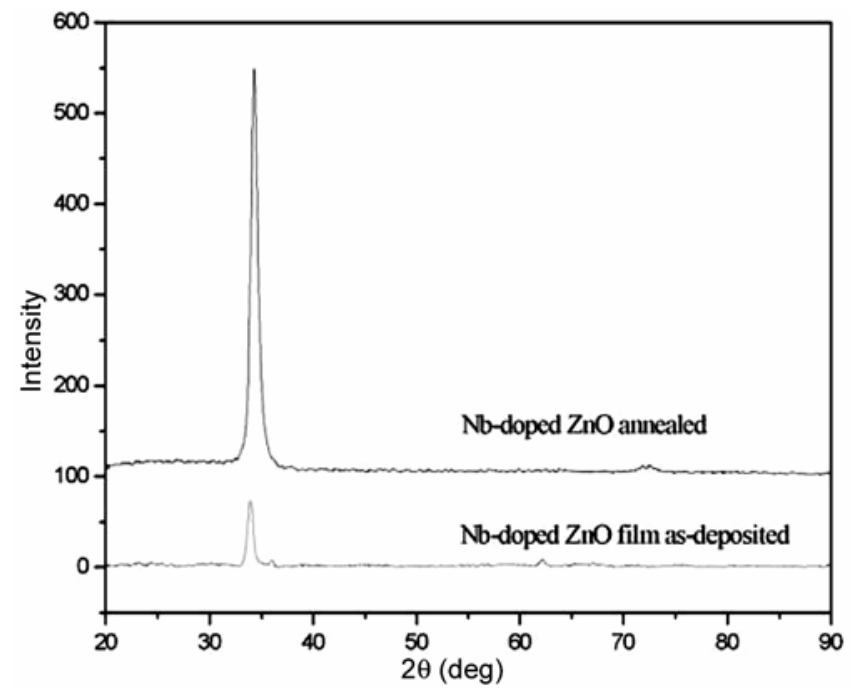

Figure 1. $\mathrm{XRD}$ diffraction patterns of $\mathrm{Nb}$-doped $\mathrm{ZnO}$ thin films.
The results of these doped thin films are in good agreement with those reported in PDF for $\mathrm{ZnO}$ (PDF75-576, $a=0.324270 \mathrm{~nm}, c=0.519480 \mathrm{~nm})$, and the peaks correspond to a hexagonal wurtzite structure. Only the (002) peaks are observed in the XRD patterns, which show that the films are highly textured along the $c$-axis and perpendicular to the surface of the substrate.
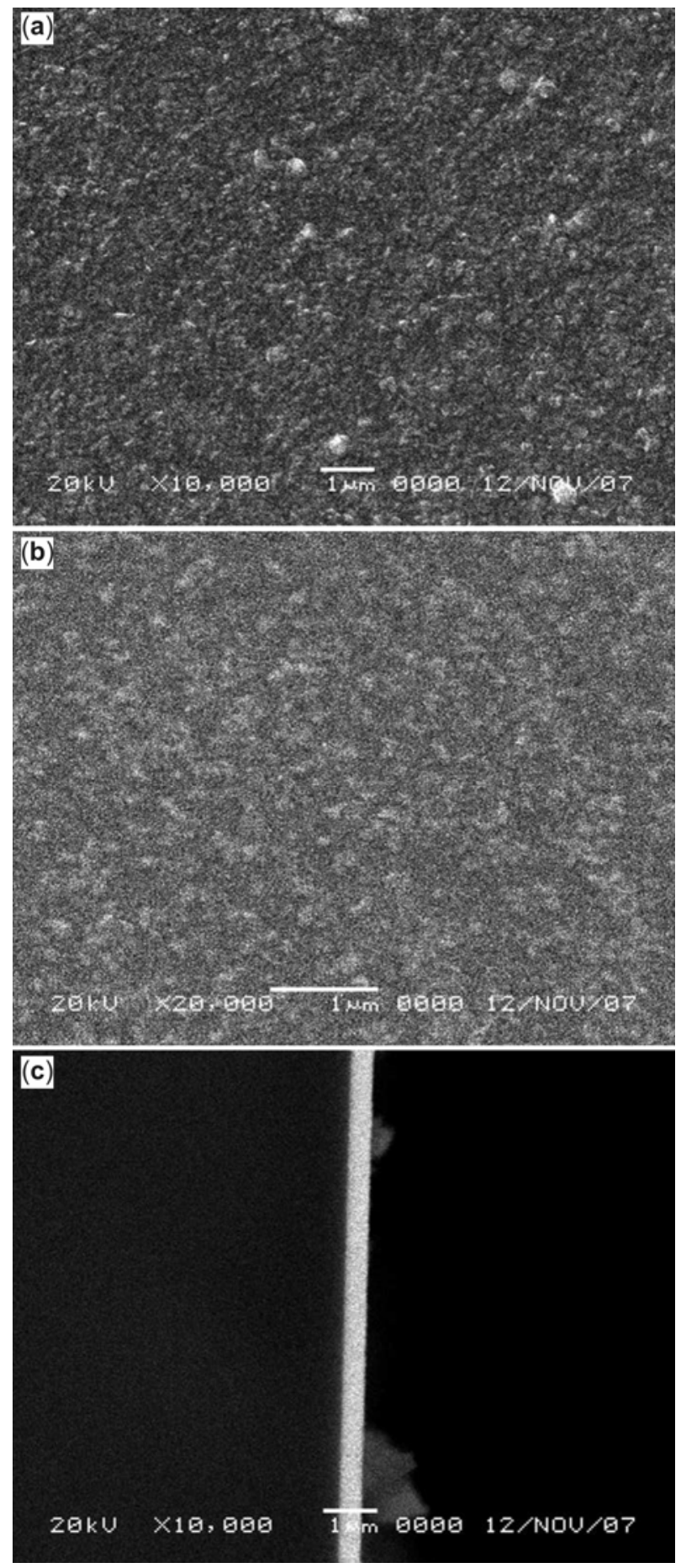

Figure 2. SEM micrographs of Nb-doped $\mathrm{ZnO}$ thin films: (a) deposited at room temperature; (b) annealed at $400^{\circ} \mathrm{C}$ for $3 \mathrm{~h}$ under vacuum and (c) the cross-section of the thin film (a). 
The Nb-doped films obtained exhibited smooth, uniform, and dense surface morphology, as shown in figure 2. In order to calculate the particle size, $g$, of the $\mathrm{Nb}$ doped films we have used the Scherrer formula (Moustaghfir et al 2003)

$$
g=\frac{0 \cdot 94 \lambda}{B \cos \theta_{\mathrm{B}}},
$$

where $\lambda, \theta_{\mathrm{B}}$ and $B$ are the X-ray wavelength (1.54056 $\AA$ ), Bragg diffraction angle and line width at half maximum. The crystallite size is in the range $15-20 \mathrm{~nm}$.

\subsection{Photoelectric properties}

The transmission spectra of the doped $\mathrm{ZnO}$ thin films (with glass substrate) prepared at room temperature is shown in figure 3 . In the visible region, all films perform high average transmittances that are more than $90 \%$ at wavelengths above $500 \mathrm{~nm}$. The transmission curve for the bare substrate is also shown in figure 3. Evidently, the absorption edge of the bare substrate is away from that of the film, and the absorption edge of the film is within the light-admitting range of the bare substrate. In the visible region, the film annealed shows the average transmittance of the order of $90 \%$, while the film as-deposited was of the order of $95 \%$. It illustrates that the annealing reduces the optical properties. It is caused by diffusing of $\mathrm{Nb}^{5+}$ into the $\mathrm{ZnO}$ layer to partially substitute $\mathrm{Zn}^{2+}$ sites at high annealing temperature and forming of an impurity energy level. So a part of visible light is absorbed by exciting the electrons of the impurity level into conduction band.

Figure 4 shows plot of $\alpha^{2}$ as a function of photon energy against $h v$ of the $\mathrm{Nb}$ doped films. As a direct

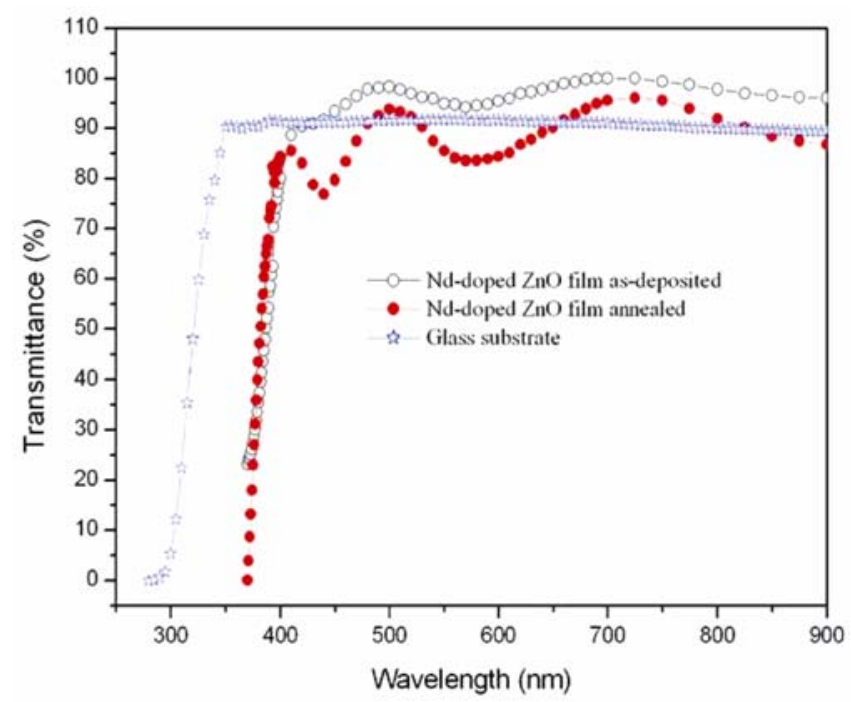

Figure 3. Optical transmission spectra of $\mathrm{Nb}$-doped $\mathrm{ZnO}$ thin films. bandgap semiconductor, the optical bandgap, $E_{\mathrm{g}}$, can be determined by the following equation (Sarkar et al 1991)

$$
\alpha=A\left(h v-E_{\mathrm{g}}\right)^{1 / 2},
$$

where $A$ is a constant dependent on the electron-hole mobility, $\alpha$ the absorption coefficient, as a function of the photon energy, $h v . \alpha$ is given by the formula (Swanepoel 1983)

$$
\alpha=(\ln 100 / T) / d,
$$

where $T$ is the optical transmittance, $d$ the film thickness. The values of the optical energy gap $\left(E_{\mathrm{g}}\right)$ is determined by extrapolating the linear portion of the curves to $\alpha=0$. By comparing with pure $\mathrm{ZnO}$ (the optical bandgap $\approx 3.37 \mathrm{eV}$ ), a shift from $3 \cdot 37-3.20$ and $3.30 \mathrm{eV}$ for the films deposited and annealed, respectively was observed. This is similar to the report of Kim and Park (2002) who observed the bandgap shift from $3 \cdot 25-3 \cdot 13 \mathrm{eV}$ for $\mathrm{Co}$ doped $\mathrm{ZnO}$ film (8\% doping concentration), and of Lin et al (2008) who observed the bandgap shift from 3.58$3.45 \mathrm{eV}$ for Gd doped ZAO film (1 wt.\% Gd doping concentration). There seems to be an increase in refractive index on annealing as seen by the appearance of fringes in figure 3. It is attributed to the amplitude of the oscillations obtained in the envelope of the film at $400^{\circ} \mathrm{C}$ annealing temperature corresponding to good-quality film, seen from figure 1.

The doped $\mathrm{ZnO}$ film shows transition from insulator to metallic behaviour. The low resistivity value of $5.47 \times$ $10^{-3} \Omega \cdot \mathrm{cm}$ for the $\mathrm{Nb}$-doped $\mathrm{ZnO}$ thin film was obtained by an annealing process of $400^{\circ} \mathrm{C}$ for $3 \mathrm{~h}$. But before annealing, the $\mathrm{Nb}$-doped $\mathrm{ZnO}$ film exhibits an insulating property. This indicates that an optimal annealing process will improve the electrical conductivity by increasing

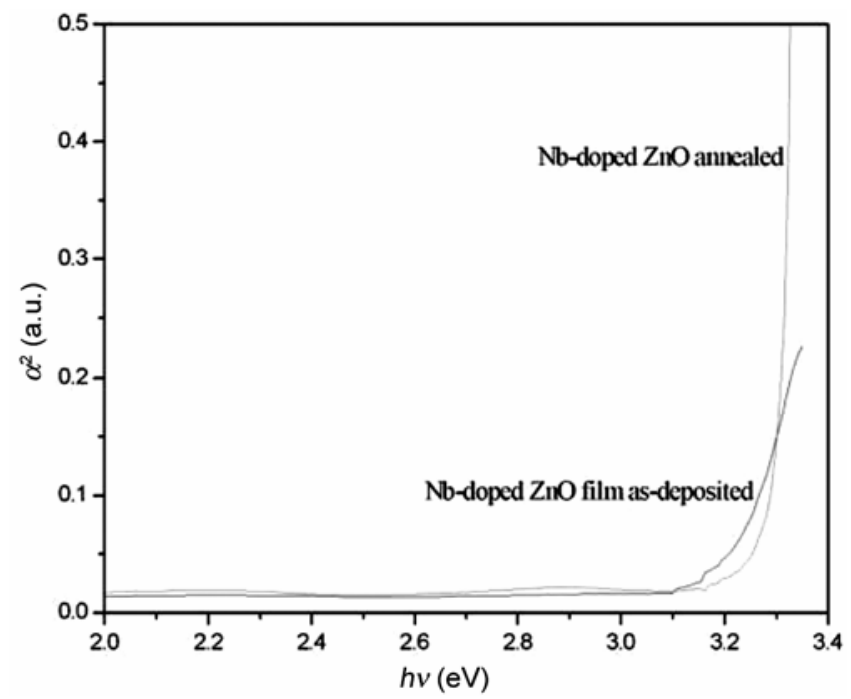

Figure 4. Plots of $(\alpha h v)^{2}$ against $h v$ for $\mathrm{Nb}$ doped $\mathrm{ZnO}$ thin films. 
the oxygen defects and reducing the grain boundary scattering (Lin et al 2008). This result is similar to the argument of Han (2002). For further improvement of properties of the $\mathrm{Nb}$-doped $\mathrm{ZnO}$ thin film, increasing sputtering powder and substrate temperature were useful (Cao et al 2009).

\section{Conclusions}

$\mathrm{Nb}$-doped $\mathrm{ZnO}$ films were prepared by rf magnetron sputtering on glass substrates at room temperature using $\mathrm{Nb}$ doped $\mathrm{ZnO}$ ceramic targets and followed by vacuum annealing at $400^{\circ} \mathrm{C}$ for $3 \mathrm{~h}$. The structural, optical, and electrical properties of the $\mathrm{Nb}$-doped films were investigated. Results show that the films exhibit hexagonal wurtzite structure with strong orientation along the $c$-axis (002). The $\mathrm{Nb}$-doped $\mathrm{ZnO}$ films possessed some excellent properties, such as high transmittance (about 90\%) in visible region, the optical bandgap is 3.20 and $3.30 \mathrm{eV}$ for the deposited and annealed films, respectively. And the low resistivity value of $5.47 \times 10^{-3} \Omega \cdot \mathrm{cm}$ for the film was obtained by an annealing process of $400^{\circ} \mathrm{C}$ for $3 \mathrm{~h}$.

\section{Acknowledgement}

The authors are grateful to the Education Department of Guangxi Zhuang Autonomous Region and Guanxi Key
Laboratory of Information Materials for supporting this research under the 200807LX121 and 0710908-09-Z grants, respectively.

\section{References}

Cao F et al 2009 Chin. Phys. Lett. 26034210

Cao H T et al 2004 Surf. Coat. Technol. 184 84J

Cui Y G et al 2005 J. Cryst. Growth 282389

Dang W L et al 2007 Superlattice Microstr. 4289

Fujimura N et al 1993 J. Cryst. Growth 130430

Han J, Mantas P Q and Senos A M R 2002 J. Eur. Ceram. Soc. 2249

Hsieh P T et al 2007 Physica B392 332

Joseph M et al 2001 Physica B302-303 140

Kim K J and Park Y R 2002 Appl. Phys. Lett. 811420

Lin W et al 2008 Rare Metals 2732

Minami T, Suzuki S and Miyata T 2001 Thin Solid Films 39839953

Moustaghfir A, Tomasella E and Amor S B 2003 Surf. Coat. Technol. 174-175 193

Özgü Ü et al 2005 J. Appl. Phys. 98041301

Paraguay F et al 1999 Thin Solid Films 350192

Saito K et al 2007 Superlattice Microstr. 42172

Sarkar A et al 1991 Thin Solid Films 204255

Srikant V and Clarke D R 1998 J. Appl. Phys. 835447

Srikant V, Sergo V and Clarke D R 1995 Appl. Phys. Lett. 36 318

Swanepoel R 1983 J. Phys. E: Sci. Instrum. 161214

Tang Z K et al 1998 Appl. Phys. Lett. 723270 